\title{
CIENCIA..., OTRA DE MIS REFLEXIONES
}

\section{SCIENCE..., ANOTHER OF MY REFLECTIONS}

José Antonio Martínez Pons: Universidad Complutense de Madrid (España). jantonio.martinez@aol.com

\section{CURRÍCULUM VITAE}

Licenciado en Ciencias Físicas (Geofísica) por la Universidad Complutense de Madrid (España) y en Ciencias Químicas (Química física) por la UNED (España). Doctor por la Universidad de Alcalá de Henares (España) en el año 2000. Profesor de la Universidad de Alcalá de Henares en el área de Química Analítica e Ingeniería Química.

\section{RESUMEN}

¿Qué es la ciencia? Es lo que busco descubrir en este artículo, según mis reflexiones. Hoy día toda forma de conocimiento pretende ser "científico", pero al mismo tiempo, científicos de título pretenden trascender su parcela y llegar más lejos. La ciencia no es infalible ni es capaz de explicarlo todo, pero es un progreso.

\section{PALABRAS CLAVE}

Ciencia - Conocimiento - Progreso 


\begin{abstract}
What is science? It's what I want to discover in this article, as my thoughts. Today, every form of knowledge intended to be "scientific", but while scientists seek to transcend his land title and go further. Science is not infallible or able to explain everything, but it is progress.
\end{abstract}

\title{
KEY WORDS
}

Science - Knowledge - Progress

\section{TEXTO:}

Muchas veces a lo largo de nuestra profesión se nos ha preguntado o nos hemos preguntado: "¿Qué es la ciencia?" Difícil pregunta por difícil, cuando no ambigua respuesta.

El término "científico" es utilizado hasta por quienes se oponen al concepto tradicional de ciencia. Ahí tenemos toda una pléyade de astrólogos, quiromantes, videntes, grafólogos, incluso abducido, que reclaman para su forma de conocimiento la categoría de ciencia; eso sí, opuesta a la ciencia que se enseña en la Universidades que, siempre según estos personajes, es toda mentira.

Sin más que levantar la cabeza entre los desordenados estantes de mi leonera de trabajo, me encuentro con títulos como "La psicología mito científico" (por favor no me conviertan el conocimiento del espíritu en el del higo, para ahorrar una p), "La falsa medida del hombre" o "Astrología física", "La física una aventura el 
pensamiento", "Sobre ciencia", o "Más allá de la física". Entre los autores: Bill Barnes, Einstein o Heisenberg.

Hoy día toda forma de conocimiento pretende ser "científico" pero, al mismo tiempo, científicos de título pretenden trascender su parcela y llegar más lejos.

En resumen, ¿qué es la ciencia? No creo que haya una respuesta clara. Si la hubiera no habría tanta ambigüedad práctica. Para mí, y con muchas dudas, es una forma de aproximación a la verdad mediante un método, el método científico (y ya hemos caído, como casi siempre que se pretende definir algo, en el círculo vicioso), cuya característica principal es llevar implícita su propia falsabilidad, es decir, grosso modo me alineo con Karl Popper. Así se me hace muy cuesta arriba aceptar que la psicología , la sociología, e incluso la economía, puedan considerarse ciencias. Si no sabemos a ciencia cierta, valga la redundancia, lo que hace un electrón, ni siquiera lo que es en verdad un electrón, ni siquiera si existe, ¿cómo pretendemos, ilusos de nosotros, saber y medir cómo funciona la mente humana?; lo cual nos las excluye como formas muy interesantes del conocimiento humano.

Por otra parte , tampoco tengo fe religiosa en la infalibilidad de la ciencia, aunque creo en su progreso, ni que las ciencias y de ellas la que más me interesa, la física, sean capaces de explicarlo todo. En resumen, para mí la ciencia es un método asintótico de aproximación a la verdad, tal vez ni eso, sino más bien una aproximación oscilando más o menos en torno a la asíntota. Ya estoy empleando el lenguaje matemático, pero, al menos desde Galileo y Newton es la mejor forma de enunciar la ciencia. Cuando ésta recurre al lenguaje "normal", una de dos o recurre a abstrusos neologismos o utiliza términos del lenguaje vulgar. Los primeros carecen de significado para la mayoría, los segundos, valga por ejemplo el "Big Bang", propuesto en tono de burla por Fred Hoyle, dan origen a interpretaciones no adecuadas. El lenguaje matemático no admite ambigüedades pero al propio tiempo 
describe, con un código exacto, algo que no es exacto y empieza otra suerte de problemas. La ciencia, pues, propone modelos, partiendo de principios que desarrolla en forma de teorías, que deben llevar implícita su propia falsabilidad. Al final toda teoría científica, por bien asentada que esté, acabará mostrándose o incompleta o simplemente falsa, aunque haya "funcionado" más o menos tiempo, incluso funcionado muy bien: calórico, éter etc., y muchas de las predicciones que en base a ellas se hicieron, primera piedra de toque de una teoría, fueran correctas. La ciencia está hecha por seres humanos utilizando fundamentalmente un instrumento "no científico", su propia mente. ¿Significa ello una contradicción en los términos? Incluso los instrumentos de medida, que son los que nos proporcionan los presuntos datos objetivos, ¿son objetivos? Conste que en este campo me siento muy próximo a Mach, creo lo que mido cuando lo mido bien, pero ¿cómo sé que estoy midiendo bien y con el instrumento adecuado?

Durante más de treinta años he estado midiendo conocimientos de mis alumnos sin un instrumento, porque la mayoría de pruebas simplemente miden unas respuestas a unas preguntas que se supone están en relación directa con los conocimientos reales, otras cosas que la ley me manda medir; para mí son inmensurables como "aptitudes y actitudes", pero ese es otro tema. Lamentablemente, con base en este conocimiento imperfecto he debido emitir un juicio bastante trascendental para el futuro de mis estudiantes. Desde luego no niego valor, por lo menos didáctico, a la interpretación ajena a los modelos matemáticos, insistiendo en que hacer matemáticas no sólo es calcular: establecer una relación "mayor-menor-igual" ya es hacer matemática; disiento pues de la postura de más de un eminente amigo, como el profesor Julio Gutiérrez, hacer física hoy día sin matemáticas es simplemente imposible. Privar a la física de la cuantitatividad es amputarle el brazo derecho. "Cualitativo es cuantativo de segunda clase", más o menos, dijo lord Kelvin. Es más, la mayoría de cuestiones "sin matemáticas" o "cualitativas" llevan implícita la cuantitatividad (la pregunta tópica ¿caen más deprisa los objetos pesados o los 
ligeros?, sería un ejemplo ya que implica, por lo menos, comparar dos velocidades, que deben medirse, y dos masas, que deben también medirse, que lo hagan con mayor o menor precisión y exactitud es harina de otro costal, pero, obviamente, cuanta mayor sea la precisión de estas medidas, más valor tendrá la respuesta).

Por supuesto, también estoy convencido de que "calcular no es entender", pero el cálculo confirma o refuta la teoría. Es curioso que tanto la psicología en sus múltiples apartados, la sociología, la economía, hasta la lingüística buscan la matematización como garantía de rigor, aunque, en mi modesta opinión, salvo herramientas estadísticas que jamás permitirán hacer predicciones individuales, carecen de instrumento de medida adecuado. (Cuando un ingeniero calcula la estructura de un avión pretende que cada avión vuele, no que un x\% aviones estadísticamente vuelen, y de hecho lo consigue). Incluso carecen del objeto medible adecuado.

Un último punto, una cosa es la ciencia y otra es su aplicación práctica. Por ejemplo, la física y la tecnología, la mecánica y la arquitectura o la biología y el arte de diagnosticar y curar enfermos. A la gente le interesa la aplicación práctica, pero sin la primera no existe la segunda y un país que descuida la formación en ciencias básicas está condenado a ser colonia, al menos tecnológica. Corramos un tupido velo sobre el famoso "Que inventen ellos" de Unamuno, aunque no creo que jamás pasara por la cabeza de Don Miguel lo que muchos han pretendido que pasara y sólo quiso manifestar su prevención hacia la excesiva materialización de la sociedad que ya entonces se veía venir. Como resumen, y siempre dentro de mi escepticismo hacia casi todo, quiero apuntar que el método científico, más que la ciencia en sí, es una forma de buscar la verdad, pero ni es la única ni siquiera la más hermosa ("Entre una teoría matemáticamente elegante y una que explique cuatro puntos experimentales , me quedo con la primera" llegó a decir Paul Dirac), aunque a su favor tiene el llevar implícita su propia falsabilidad. 
Vaya..., que entre poético modelo del Génesis y el complejo conjunto de ecuaciones del universo inflacionario, las singularidades iniciales y el tiempo antes del tiempo, tengo mis dudas, aunque no dudo de que dentro unos años, siglos quizás, ambas interpretaciones estarán en el mismo cajón de lo demodé. Tal vez fuera bueno dejar pues cada cosa en su sitio y que cada palo aguante su vela.

Estas líneas, en que no he aclarado demasiado, quizás porque yo tampoco tengo las ideas demasiado claras, no pretenden ser sino una contribución más al pequeño intercambio de pareceres sobre el tema, siempre enriquecedor, y ahí quedan.

Nota: Las citas de este texto, conjunto de reflexiones a vuela pluma, son todas de memoria. 